\section{Diagnóstico y tratamiento de las Enfermedades Digestivas}

Edición 2013. Editorial IKU (497 páginas) ISBN 978-956-7936-20-5

Con muchísimo agrado quisiéramos comentar la aparición de la esperada 3a Edición del Libro: "Diagnóstico y Tratamiento de las Enfermedades Digestivas". Este libro, al igual que en las ediciones previas, ha tenido por editores a los Drs. Juan Carlos Weitz, Zoltán Berger, Samuel Sabah y Hugo Silva. El Editor Jefe (Dr. Weitz) y su comité editorial se han esmerado en la edición, revisión y diagramación de este libro, y han tenido un gran acierto con los autores que han elegido para presentar en forma muy completa, actualizada y amena los distintos capítulos de las enfermedades del Sistema Digestivo. Cada capítulo tiene un ordenamiento muy homogéneo, con definiciones, epidemiología, etiopatogenia, aspectos clínicos, diagnóstico, prevención y tratamiento.
Este libro tiene más de 50 capítulos escritos por distinguidos especialistas de nuestra Sociedad Chilena de Gastroenterología (SCHGE), más de 500 páginas muy actualizadas, Tablas, Figuras y Referencias relevantes para cada capítulo. Por lo mismo, creemos que se constituye en un gran aporte para el médico internista, cirujano, residente en formación, gastroenterólogo y, sin duda también, un libro de consulta para el alumno de Medicina durante su formación de pregrado. Tiene aún un tamaño adecuado y de bolsillo para una consulta fácil y expedita. Con este libro la SCHGE cumple uno de sus más importantes objetivos, que es difundir el conocimiento de las enfermedades digestivas y contribuir al conocimiento y actualización de los médicos, tanto especialistas como no especialistas.
Dr. Rodrigo Zapata L. Presidente, Sociedad Chilena de Gastroenterología 